relieving the exquisite neuralgia which so often affects the heel in long-standing cases, and the sloughing of the integuments from pressure. A very slight movement of the tapes will effect this without the least displacement of the fractured ends of the bone. I may here mention, that in the accompanying woodcut the angle of incidence of the planes is made to appear too great, owing to a mistake of the artist. An apparatus made exactly according to the drawing would not produce any material elevation of the limb, but it serves very well to explain the action of the machine.

Mr. Weiss of the Strand, at whose house the apparatus may be seen, has undertaken to construct it, after a pattern I sent him, and to explain its use according to the directions which accompanied the model. It may also be obtained of Mr. Laundy in the Borough.

I conclude with some general directions for its application :-A piece of deal board, about eight inches widle, must be placed across the bedstead, on whose frame it would rest at the distance of about eighteen inches from the foot; over this are to be placed the mattress, bed, and sheets. 'The cross bar of the machine is then to be placed in a line parallel to and over this board, of course the mattress, \&c. intervening. On placing the limb upon the machine, it will be seen that the weight of the body depresses the long lever at $C$, and therefore raises the lower part of the apparatus, in consequence of the board across the bars of the bed preventing the depression of the machine at $A$. Its action may be said altogether to depend upon the movement of the long lever anterior to the cross bar upon the bar itself.

I will not occupy your valuable pages at greater length, trusting you will allow me in a future number to make some further observations on the cases of compound fracture in which I have used my invention with success; as well as some remarks upon its application to the treatment of simple fractures without splints, and of some other injuries affecting the lower extremity.

\section{SLOUGHING OF THE BLADDER.}

\section{SLIPPING OF A BOUGIE INTO THE BLADDER.}

TO THE EDITORS OF THE FROVINCIAL MEDICAL AND SURGICAL JOURNAL.

Gentlemen,-As a member of the Provincial and Surgical Association, I have, since August last, regularly received the Provincia l Medical and Surgical Journal. I believe the intention of the hebdomadal supply of that Journal to the members of the association was, that they may have an opportunity of seeing, and, if they thought proper, of publishing any cases of interest that might occur in their practice, but may not be of sufficient interest or importance to have a place in the annual report. Should you consider the following of that class, you will oblige me by giving it a place in an early number of your Journal.

On the 4th ult., about 10 o'clock P.M., I was requested to call on Mrs. D., a little woman whom I had attended five or six times before; she was then in labour with her eighth child; she generally had very untoward times, and always very large children.
I found the pains very strong and regular; on the first examination, I accidentally ruptured the membranes, and an unusual quantity of liquor amnii escaped; on proceeding, I found the os uteri amply dilated, and the head presenting; the pains were not quite so strong or frequent after the waters were discharged, still they continued pretty regular till 8 o'clock the next morning, without advancing the labour; I then left her, and returned again about 11 o'clock; there had been no pain during my absence, and the child's head had scarcely passed the brim of the pelvis; there was a sort of point formed by the scalp protruding into the cavity of the pelvis. This was the only progress that had been made in the thirteen hours from the time I first saw the patient, and I learned from the nurse, that she had had very strong pains during the whole of the day before I was sent for; as the pains had gone off, and the poor woman seemed worn out for want of rest, I saw no good in further delay. I therefore gave the family to understand that there was no chance of her giving birth to a living child, and that, in order to save the mother, it would be necessary for me to have recourse to artificial means; they readily gave their consent; finding that I could do nothing with the forceps, I at once proceeded to perforn the operation of craniotomy. Having relucerl the size of the child, the delivery was completed with the blunt hook without much difficulty, except a little trouble with the shoulders, the child being a very large one. The patient continued to go on very well until the 10th, six days after the delivery, when I was sent for; on my arrival, I was informed that in the night there had been a very great discharge, but not coloured, (the lochial discharge had nearly stopped;) so much, that it had saturated the bed, and the woman was wet up to the shoulders,-this was the expression of the nurse; there was no pain previous to the discharge, and it occurred without the woman being aware of it. On passing the hand over the abdomen, there was no pain on pressure, nor did it seem to increase the discharge. There appeared to be no constitutional symptoms to demand any particular treatment. I merely ordered the band.. age round the body to be drawn a little tighter, and as the bowels had not been opened, I sent a mild aperient draught. The next day I found that the discharge still continued; I inquired if the patient had made water in the night; she said very little, but she thought it passed away from her by the smell of the napkins. 'Thinking that there must be some loss of power about the neck of the bladder, I gave her to understand that it would be necessary for me to ascertain what really was the matter, by an examination, and perhaps to introduce the catheter into the bladder; this was objected to, as she thought she might be better. The next day, however, I was allowed to pass a small silver catheter, which was done without any pain or difficulty; finding that no water escaped, I introduced my finger into the vagina, and soon discovered the true nature of the accident; I felt the end of the catheter projecting into the vagina instead of being in the bladder, and to my great surprise a large opening in the neck of the bladder into which I could pass two fingers; it seemed to be of a triangular shape, and from its jagged feel I should say that the aperture had been caused by sloughing; but before this took place, there must 
have been inflammation, and one would suppose much pain in the part, but I had heard no complaint whatever. I must confess that I was much surprised at finding so much mischief had been produced, and astonished that such a breach had been made in such an extremely irritable organ as the bladder, without causing more pain and inconvenience to the patient; all she complained of was a little heat about the vagina, and scalding; she sat up two or three times after the urine escaped, and in that position it did not run off so freely, but the moment she lay down, the bladder seemed to empty itself. Being fully satisfied of the nature and extent of the disease, the next thing was to set about the cure; in attempting this I was rather discouraged by what I had read and heard, and there was also a great reluctance on the part of the patient to having anything mechanical done; at last she consented, and I introduced rather a largesized gum-elastic catheter through the urethra into the bladder: this had the effect of dividing the urine and scattering it about the vagina, but none passed through the catheter. Being fully satisfied that the catheter was in the bladder, I contrived to keep it there by tying a piece of tape to it, and then fastening it round the body and thighs; this was about 12 o'clock in the day; at 11 P.M. I called, and still found the urine running away, but the nurse said she thought she saw a little drop from the catheter. 'The woman was restless, and complained for the first time of a smarting pain in the passage, and wished me to withdraw the catheter; fearing the consequence of its running all night, I did so, and it was very evident, by its dripping when removed, that some urine was left in the bladder. I ordered her to continue the mixture she was taking, which contained morphine, spirit of nitrous rether, and camphor mixture, and left her for the night; next morning I was gratified at finding that there had been but a very little discharge of urine, and that she had passed a very small quantity twice in the natural way, and continued to do so all the day. The next day I fancied that there was a little fulness over the region of the bladder; fearing that any distension of the organ might produce fresh mischief, I attempted to pass the catheter again, but finding some little resistance I desisted, thinking I might do harm by persevering; the discharge of urine from the vagina grew less daily for about five days; the woman now makes water as well as ever, and suffers no inconvenience from what has occurred, except a sensation of feeling as though she wanted to make water when in an erect position.

Whilst I am on the subject of the urethra and bladder, I will relate a case that came under my care a few years since. I was consulted by a stout, rolbust exciseman, who seemed to be fond of tasting as well as gauging exciseable liquors, and when under the influence of it he was subject to retention of urine; he was half drunk when I saw him; the bladder was much distended, and the poor fellow appeared to be in great agony. He had been in the habit of passing a bougie himself, but that day he had not been able to get it into the bladder. On my producing the bougies, he pointed out the size of the one he had been in the habit of using, and without much difficulty or inconvenience $I$ got it past the stricture, which no doubt was only spasmodic. I wished him to let the bougre remain a minute or two in the urethra, but at that moment I was called out of the surgery, and was absent about five minutes, not more. On my return I found the exciseman laid back in the chair, snoring away, with the penis erect, but no bougie visible. I roused him, and inquired for the instrument. His reply was, that he had left it in the passage, but it was not to be seen. I now examined the penis, and about an inch and a half down the urethra I felt the end of the bougie. I tried to force it out, but in so doing altered its form. The heat of the part had so softened it, that I flattened the end by taking hold of it. The poor fellow became very much frightened. While I was deliberating on what to do, he had a strong desire to make water, accompanied by a sort of spasmodic jerking, which seemed to move the bougie. 'This continued at intervals of two or three minutes, till at last $I$ had the satisfaction of seeing the end of the bougie peeping out of the urethra, and, as you may suppose, I took good care that it did not get out of sight again. On removing it, more than a quart of urine escaped.

I am aware that there is nothing very extraordinary in the medical or surgical treatment of either of the above cases, but the knowledge of the successful termination of two not very common accidents may tend to cheer and to give confidence to the practitioner who may be so unfortunate as to mect with similar cases in his practice, and this is the only object I have in view in drawing them up for publication.

\section{I am, gentlemen, \\ Your obedient servant,} George King.

Bath, Oct. 16, 1841.

\section{RUPTURE OF THE UMBILICAL CHORD.}

TO THE EDITORS OF THE PROVINCIAL MEDICAL AND SURGICAL JOURNAL.

Gentemane,-If you think the following accident in midwifery worth noticing in your weekly journal, it is much at your service. Perhaps it furnishes a hint both to practitioners and nurses.

Your obedient servant,

\section{E. Copeman.}

A short time since, I was summoned in haste to attend Mrs. C. in labour. I had previously had intimation that her labours were generally very quickly over, and therefore hastened to her assistance with as little delay as possible. When I arrived, however, I found it " all over," the child born and dressed, and the placenta removed. The patient was pale and faint, having, as I understood, lost a good deal of blood before the expulsion of the placenta. On my making inquiries about the infant, the nurse put on a countenance portentous of mischief, real or imaginary, such a one as accoucheurs desire not to look upon, though often doomed to behold. She told me she had been much frightened, and that someching was "very wrong" with the child. The cause of her alarm was as follows: the umbilical cord had been twisted about the neck and lwdy of the child, and being very thin, and the child forced into the 